\title{
New branches for old roots
}

\author{
from Barry Cox
}

THE battle seems now to have been joined in earnest. Waving their branching weapons of attack, some of the cladists are now assaulting even the most fundamental roots of the systems of relationship that the traditional evolutionary morphologists have developed. After the skirmish over the tetrapod-origin outpost, in which Rosen et al. (Bull. Am. Mus. nat. Hist. 167, $159 ; 1981)$ suggested that lungfishes rather than rhipidistians were closest to tetrapod ancestry, Gardiner has now used cladistic techniques to transform the whole system of tetrapod classification (Zool. J. Linn. Soc. 74, 207; 1982).

Gardiner's method is first to return to the criteria given by nineteenth century anatomists in their analyses of relationship of the major tetrapod groups. Thus he concludes that "the denial of any immediate relationship between the mammals and the other great homotherm (sic) group, the birds, was based on no more than three characters; the form of the heart, aortic arches and occipital condyle". These three characters he swiftly demolishes (in about a page of text), and immediately moves on to list a number of characteristics of homoiothermy and of the central nervous system that appear to link mammals and birds as sister-groups. He relates to these two, in order of increasing distance, the crocodiles, chelonians and lepidosaurs. In all these discussions, palaeontology is ignored and only the characteristics of living animals are used. Into the resulting classification, Gardiner then fits a few fossil groups, such as the pterosaurs (a sistergroup of birds), dinosaurs in Owen's original sense (sisters to crocodiles), the cynodonts (far divorced from the mammals), the dicynodonts (sister-group to the chelonians) and the pelycosaurs (completely separated from the previous two groups). The results are so different from those that also incorporate palaeontological data that a headlong collision is inevitable, for there can be no minor shifting of viewpoints or emphasis that could lead to a reconciliation or synthesis.

Gardiner's methods can be illustrated particularly well in his treatment of the Synapsida, the splitting of which into three separate groups (pelycosaurs, dicynodonts and cynodonts) is, to a palaeontologist, one of the most revolutionary aspects of his work. Basically, he rejects previously established relationships if he can quote other workers to the contrary and can show that some members of any other group also share some of the features previously thought to support the accepted relationship. So "as long ago as 1926 Berg wrote that the mutual similarities between mammals and (advanced synapsids) were probably due to convergence" and "despite the fact that fenestrae might have arisen independently (as they have done within the Chelonia ... and Amphibia .), today's unquestioned doctrine is that the Synapsida include the mammal's closest relatives"'.

Gardiner also underestimates the modern palaeontological evidence by restricting himself to out-dated authors; is it really true of the pelycosaurs that "Their claim to Synapsid relationship apparently rests on Cope's (1884) insistence on their closeness to mammals and the possession of a lateral temporal fenestra"? Reisz, himself a cladist, states that "The pelycosaurs, together with their descendants, form a natural group and possess such derived characters as broad anteriorly tilted occipital plate ... reduced posttemporal fenestrae, single median postparietal, and septomaxilla composed of a broad base and a dorsal process" (Spec. Vol. Syst. Ass. 15, 553; 1980). The relationships of pelycosaurs to both dicynodonts and cynodonts (and also to other therapsid and theriodont groups) is also suggested by the fact that all these groups share with sphenacodontid pelycosaurs the synapomorphic feature of a reflected lamina on the angular bone of the lower jaw. All, except the turtle-beaked dicynodonts, also share in having a heterodont dentition.

The cynodonts, like some other advanced synapsids, show a progressive reduction of the post-canine dentition and of the post-dentary bones of the lower jaw, with the mammalian type of squamosaldentary jaw articulation having evolved in a few forms, and various approaches to the mammalian condition in the secondary palate, dentition, limbs and girdles. Gardiner nevertheless dismisses any relationship between cynodonts and mammals because an examination of the British Museum (Natural History) specimens of the cynodont Thrinaxodon "failed to

Barry Cox is a Professor in the Department of Zoology, King's College, University of London, London WC2. reveal a single mammalian synapomorphy" and, for example, showed that Thrinaxodon was not particularly mammalian in its tooth-replacement and braincase. But it is such later, mid-late Triassic cynodonts as Probainognathus and the trithelodonts that are thought to be close to the origin of mammals, and these do show far more mammalian conditions of the teeth and braincase.

It seems perverse to reject these complex similarities merely because our extensive knowledge of the osteology of both recent and fossil tetrapods reveals isolated instances where temporal fenestrae have evolved independently (and, in any case, the chelonian openings that Gardiner quotes are emarginations, not fenestrae). We have no such systematic knowledge of the soft-part anatomy, physiology or biochemistry that make up the 17 characters that Gardiner lists to support his contention that birds and mammals are closely related sister-groups. As Szalay ( $\mathrm{Am}$. Zool. 21, 37; 1981) has commented: "I believe that at the very heart of the postHennigean cladistic approach to phylogeny reconstruction lies the implicit neglect for biological and functional scrutiny of the characters employed. As a result of this attitude the postulated homologies chosen (the units on which phylogenies are based) are not biologically investigated and therefore the chances of discovering whether these features are unique or parallel or convergent acquisitions, or whether they represent a pattern commonly attained by distant lineages because of epigenetic factors, or because they are rooted in a common heritage, weakens the very foundations of such analyses. In other words, character analysis commonly practised in cladistics is really a semantically masqued enumeration of characters without attempts to analyse and weight them".

Gardiner's suggestions are so completely at odds with the palaeontological record that some of Panchen's observations, in an incisive criticism of the cladistic method published in the same volume as Gardiner's work (Zool. J. Linn. Soc. 74, 207; 1982), seem particularly relevant. "The first obvious fault of cladism in general is perhaps a temperamental and, one may hope, a temporary one. This is the temptation to produce new and revolutionary groupings of organisms, or to resurrect old and discredited ones, just to demonstrate that cladism is getting results." 